\title{
ASSESSMENT OF TWO HERBICIDE WIPING DEVICES
}

\author{
K.C. HARRINGTON, M.Z. HOOD and K.C. McKINNON \\ Institute of Natural Resources, Massey University, Private Bag 11-222, \\ Palmerston North
}

\begin{abstract}
If herbicides were wiped on to weeds rather than sprayed, the risk of spray drift would be eliminated. Two devices designed to apply herbicides using rolling wipers were assessed for their ability to apply constant amounts of herbicide to treated surfaces. The Weed Ball Applicator treated strips only $36 \mathrm{~mm}$ wide despite having a roller $100 \mathrm{~mm}$ wide, whereas the Turf Girl applicator delivered a $500 \mathrm{~mm}$ wide band. Both applicators suffered from a tendency to apply less herbicide as the herbicide reservoir emptied, with the nearly empty Weed Ball delivering only $12.4 \%$ of that applied when full. Adjustments to the flow rate as the reservoir emptied could be made using a tap in both devices. A field evaluation of the Weed Ball applicator on dichondra showed that it had good potential for selective localized applications of herbicides to lawn weeds. Of the treatments evaluated, a metsulfuron solution $(0.45 \mathrm{~g} /$ litre $)$ gave the best control.
\end{abstract}

Keywords: chemical application, volume rate, wiping devices, dichondra, Dichondra micrantha.

\section{INTRODUCTION}

When applying selective herbicides to turf through conventional spraying equipment, there is often a risk that nearby desirable ornamental plants may be damaged by spray drift. There are two commercially available herbicide application devices in New Zealand that might be suitable for treating turf weeds by wiping chemical on to weeds from rollers instead of spraying. One of these devices, the Turf Girl Elimiweed Contact Weed Killer (hereafter called the Turf Girl applicator; Fig. 1a), is specifically marketed for selective control of turf weeds. The other device, the Weed Ball Application System (hereafter called the Weed Ball applicator; Fig. 1b), is marketed for spot-treatment of weeds in urban areas, primarily with glyphosate. By wiping herbicide on to weeds rather than spraying, the risk of damage to nearby nontarget vegetation would be almost eliminated and treatment under windy conditions would be possible.

Many of the selective herbicides used in turf can scorch the grass if too much is applied, and give poor weed control if insufficient is applied. Thus, a uniform flow of herbicide from an applicator is more important for selective weed control than when spot-spraying non-selective herbicides where any rate above a certain threshold will provide the required result. This paper reports on our assessment of the suitability of these two devices for applying selective herbicides to turf. The uniformity of herbicide delivery was measured from both applicators, then the Weed Ball applicator was used to test the suitability of several herbicides for spot-treating weeds in dichondra (Dichondra micrantha) lawns.

\section{Uniformity of output}

\section{MATERIALS AND METHODS}

The output of solution from the Weed Ball applicator was measured by filling it with water then rolling it for $60 \mathrm{~m}$ across dry concrete at a constant speed of $1.2 \mathrm{~m} / \mathrm{sec}$. Application of solution was calculated by weighing the applicator before and afterwards. Measuring herbicide output from the Turf Girl applicator involved running the roller 

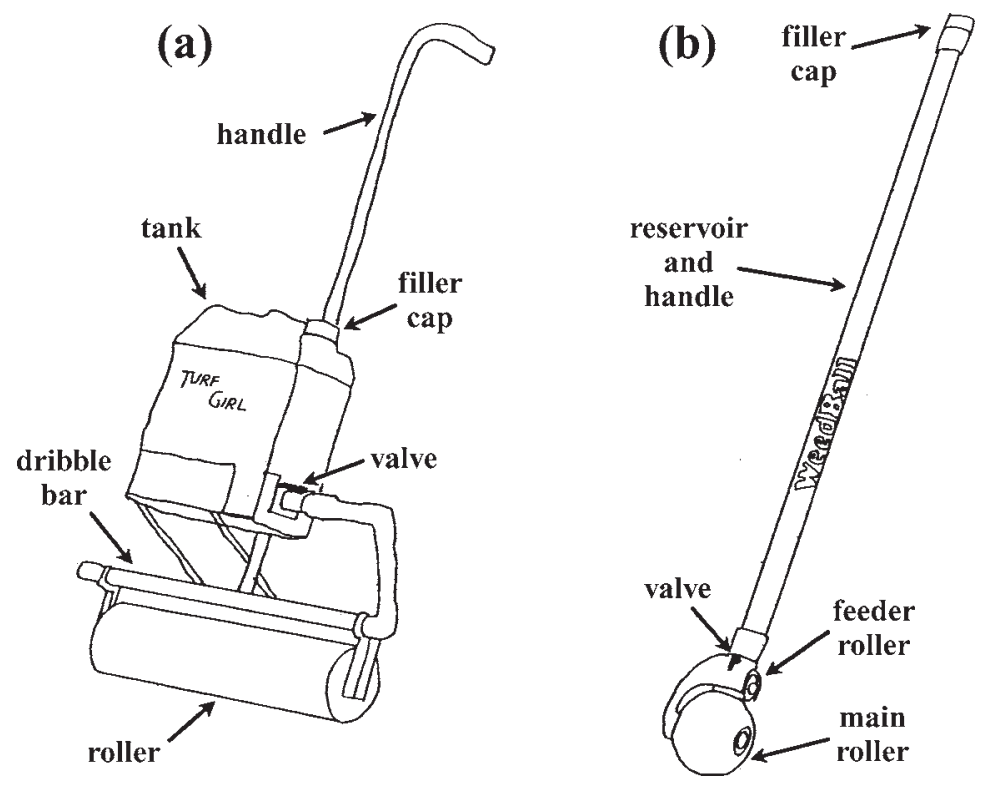

FIGURE 1: Diagrams of the (a) Turf Girl applicator and (b) Weed Ball applicator.

across a dry sheet of $600 \mathrm{~mm}$ by $400 \mathrm{~mm}$ Perspex at $1.2 \mathrm{~m} / \mathrm{sec}$ and weighing this immediately afterwards. The rate of application was compared when the applicators were full (11.5 litres for the Turf Girl applicator and $800 \mathrm{ml}$ for the Weed Ball applicator), and partially full (3 litres for the Turf Girl applicator and 400 or $100 \mathrm{ml}$ for the Weed Ball applicator). All measurements were replicated 10 times. As the flow rate from the Turf Girl applicator could be restricted by using the valve at the base of the tank (Fig. 1a), attempts were made to keep output constant as the tank emptied by adjusting this.

\section{Application to dichondra swards}

The adequacy of the Weed Ball applicator for applying selective herbicides to localised weedy areas in lawns was tested by marking out line-transects within a weedinfested dichondra lawn and applying several herbicide treatments (Table 1) along the lines. Herbicides tested were clopyralid (Versatill), glufosinate (Buster), glyphosate (Roundup), metsulfuron (Escort) and tribenuron (Granstar). Each treatment was applied to three different line transects, each $3.0 \mathrm{~m}$ long, on 2 September 1998. The Weed Ball applicator was run down one side of the line transect and back along the other side at $1.2 \mathrm{~m} / \mathrm{sec}$, doubling the width of the treated strip. A new foam ball was fitted to the applicator for each herbicide type to avoid contamination of treated areas by previous chemicals. Flow rate was restricted using the tap to 80 litres/ha, and application rates were determined using results from past research (Harrington and Zhang 1997). The herbicide treatments were compared to untreated line transects. The transects were scored on a regular basis over subsequent weeks to quantify damage to the dichondra and also each of the individual weed species present.

\section{Uniformity of output}

\section{RESULTS AND DISCUSSION}

Due to the shape of the ball on the Weed Ball applicator, herbicide solution was only applied in a strip $36 \mathrm{~mm}$ wide, despite the ball being $100 \mathrm{~mm}$ in diameter. The 
amount of solution applied by the Weed Ball applicator was quite consistent when the solution was topped up to the same mark in the reservoir before each application. However, output dropped markedly as the reservoir emptied. When the reservoir was full, the output (mean value with standard error in parentheses) over $60 \mathrm{~m}$ was equivalent to $514( \pm 19)$ litres/ha. When half full, output was $336( \pm 12)$ litres/ha, a $35 \%$ decrease. When the reservoir contained only $100 \mathrm{ml}$, application was equivalent to $63.7( \pm 3.0)$ litres/ha, representing an $88 \%$ reduction in output. Partially closing the tap when the tank was full could give similar outputs to when the tap was fully open and the tank partially empty.

The Turf Girl applicator wiped herbicide on the ground over a $500 \mathrm{~mm}$ wide swath. When travelling across uneven ground though, weeds in the hollows escaped treatment. Herbicide solution was dribbled on to the roller from a perforated pipe immediately above the roller (Fig. 1a). If the ground was sloping, more solution came out of holes from the lower end of the pipe, leading to uneven wetting of the roller. These problems could be partially overcome by ensuring weeds were not mown too short prior to application, and travelling directly up slopes rather than sideways along them. As the outlet pipe comes out the side of the reservoir rather than the bottom, it was difficult to use the final 1.5 litres of solution from the container.

A decrease in application rate also occurred with the Turf Girl applicator as the reservoir emptied, due to a reduction in the pressure with which solution was pushed down into the dribble bar. When full (11.5 litres), the application rate was equivalent to $214( \pm 11.0)$ litres/ha, but this dropped to $89.1( \pm 13.8)$ litres/ha when the tank contained only 3 litres, a 58\% decrease. Another factor which could decrease application rate as the tank emptied was the inability of air to get into the tank if the filler cap was tightly in place, resulting in a partial vacuum in the tank which slowed rate of herbicide discharge. This problem has been overcome in the Weed Ball applicator by including a venting valve in the filler cap. In our experiments, the filler cap of the Turf Girl applicator was left loose to avoid any vacuum forming. Increasing the walking speed with either applicator also decreased the application rate.

In experiments to overcome the decrease in application rate as the Turf Girl emptied, the best position of the tap was judged by visually assessing output after running the applicator over dry tarmac. The position was then recorded, and output was checked using the perspex as described earlier. This process was repeated for several different reservoir levels. Eventually the applicator was calibrated so that, by adjusting the tap as the reservoir level dropped, there was no significant difference $(\mathrm{P}=0.05)$ between rates delivered as the tank emptied. Average application rates were equivalent to 182 litres/ha when 10 litres was in the tank, 187 litres/ha at 7.5 litres and 191 litres/ha at the 5 litres position.

\section{Application to dichondra swards}

The herbicides applied to the dichondra are all normally non-selective herbicides but, apart from the metsulfuron, have been shown in past trials to be tolerated reasonably well by dichondra at low rates (Harrington and Rahman 1998). The Weed Ball applicator appeared to apply the herbicides uniformly, as determined by the extent of damage to plant species along each line. The dichondra suffered little damage from most treatments, though the glufosinate and high rate of glyphosate were not tolerated well at the rates used (Table 1).

The effect of the herbicides on the weeds present became more difficult to determine as weeks passed by, because the band treated by the applicator was so narrow that untreated weeds beside it soon grew laterally into the band. This did not occur with the metsulfuron though, which presumably moved laterally in the soil after application, causing a much wider band of weed control (approximately $200 \mathrm{~mm}$ ) than the other herbicides which have little if any soil persistence.

All herbicide treatments controlled the main two weed species present, namely white clover (Trifolium repens) and turf speedwell (Veronica serpyllifolia). Although metsulfuron appears less effective in Table 1, it had a slower effect than other herbicides and did eventually give very good control of clover at both rates used. Of the many other weed species present, metsulfuron controlled the broadest range with 
least damage to the dichondra. However, it did not control grasses, toad rush (Juncus bufonius) or umbrella sedge (Cyperus eragrostis).

TABLE 1: The effect of herbicides from a Weed Ball applicator on treated dichondra, white clover and turf speedwell as assessed by scoring ( 1 = dead, 8 = unaffected $)$ six weeks after treatment.

\begin{tabular}{lcccc}
\hline & \multicolumn{2}{c}{ Rate } & \multicolumn{3}{c}{ Health of plants } \\
\cline { 2 - 5 } Active ingredient (a.i.) & (g a.i./litre) & Dichondra & Clover & Speedwell \\
\hline metsulfuron & 0.22 & 7.7 & 3.3 & 4.0 \\
metsulfuron & 0.45 & 6.7 & 3.3 & 2.0 \\
glyphosate & 6.7 & 6.3 & 7.0 & 5.0 \\
glyphosate & 13.5 & 5.0 & 1.7 & 1.0 \\
clopyralid + tribenuron & $3.7+0.19$ & 7.7 & 2.7 & 4.7 \\
clopyralid + tribenuron & $7.5+0.37$ & 7.7 & 3.0 & 4.7 \\
clopyralid + tribenuron & $15+0.75$ & 7.3 & 1.0 & 1.7 \\
glufosinate & 12.5 & 5.0 & 3.7 & 1.7 \\
glufosinate & 25 & 1.7 & 1.3 & 1.0 \\
untreated & & 8.0 & 8.0 & 7.7 \\
LSD (P=0.05) & & 1.9 & 3.8 & 3.6 \\
\hline
\end{tabular}

\section{Overall assessment}

Both of the applicators show good potential for applying selective herbicides to weeds in turf to minimise spray drift, but only if carefully calibrated so that output can be changed as the reservoir empties. If the taps are not adjusted as the reservoirs empty, there will either be too much herbicide applied when the reservoir is full or insufficient application when nearly empty. This constant need for adjustment of the tap does not make them easy to use. The Weed Ball applicator is better suited to treating individual weeds as it can be lifted off the turf between each weed. However, some selective grass turf herbicide formulations such as MCPA, 2,4-D and triclopyr/picloram (Tordon Brushkiller) cause swelling of the Weed Ball rollers and so cannot be used (R. Moore, pers. comm.). The Turf Girl applicator is more suited for blanket application of herbicides to small lawns, to turf beside flower gardens or to extensive patches of weeds.

\section{REFERENCES}

Harrington, K.C. and Rahman, A., 1998. Tolerance to herbicides of ground cover species for New Zealand orchards. Plant Prot. Quarterly 13: 111-116.

Harrington, K.C. and Zhang, T., 1997. Herbicides for controlling weeds in Mercury Bay weed. Proc. 50th N.Z. Plant Prot. Conf.: 462-466. 